\title{
Qualidade de beterraba de mesa (Beta vulgaris) em função de fontes e doses de
}

\section{potássio}

Quality of table beets (Beta vulgaris) as a function of potassium sources and doses

Calidad de la remolacha de mesa (Beta vulgaris) en función a fuentes y dosis de potasio

\author{
Marcos Fabian Sanabria Franco \\ ORCID: https://orcid.org/0000-0002-7820-9037 \\ Universidade Federal de Viçosa, Brasil \\ E-mail: marcosfabiansanabria@gmail.com \\ Leonardo Angelo Aquino \\ ORCID: https://orcid.org/0000-0002-7764-730X \\ Universidade Federal de Viçosa, Brasil \\ E-mail: aquino.ufv@gmail.com \\ Willian Rodrigues Macedo \\ ORCID: https://orcid.org/0000-0003-4660-913X \\ Universidade Federal de Viçosa, Brasil \\ E-mail: willian_rmacedo@yahoo.com.br \\ Fabrícia Queiroz Mendes \\ ORCID: https://orcid.org/0000-0003-3555-8162 \\ Universidade Federal de Viçosa, Brasil \\ E-mail: fabricia.mendes@ufv.br \\ Enrique Ulises Arceda \\ ORCID: https://orcid.org/0000-0002-7647-3686 \\ Universidade Federal de Viçosa, Brasil \\ E-mail: arceda14@gmail.com
}

\begin{abstract}
Resumo
Objetivou-se avaliar a qualidade da beterraba de mesa (Beta vulgaris) em função da fonte de potássio. O experimento foi conduzido na Universidade Federal de Viçosa - Campus Rio Paranaíba - MG. Foram conduzidos dois experimentos nas épocas de verão e de inverno e com a mesma matriz experimental. As fontes estudadas foram o cloreto de potássio, o sulfato de potássio e o nitrato de potássio. As doses de K foram de 60, 120 e de $240 \mathrm{mg} / \mathrm{dm}^{3}$ de K. O tratamento adicional foi a testemunha sem aplicação de K. Os fatores em estudo foram combinados em esquema fatorial $(3 \times 3)+1$ e distribuídos em blocos ao acaso com seis repetições. A qualidade foi positivamente alterada pela adubação com K, independente das fontes aplicadas. A adubação com K resultou em maior acidez, melhor firmeza, maior intensidade da cor $\mathrm{L}^{*} A$ e $B$ e aumento linear de sacarose. Após armazenamento essas variáveis foram reduzidas em raízes sem adubação com $\mathrm{K}$ e mantidas quando houve adubação. A qualidade das raízes (sólidos solúveis, textura e sacarose) das plantas cultivadas em inverno foi maior do que as de cultivo de verão, sem influência expressiva da fonte de K. Após serem armazenadas, as raízes das plantas cultivadas no inverno apresentaram aumento da concentração de sacarose, intensidade da cor ( $\left.\mathrm{L}^{*}\right)$, acidez e sólidos solúveis em função de doses. Assim, conclui-se que as fontes de $\mathrm{K}$ não apresentam efeitos significativos na qualidade na colheita e após o armazenamento na beterraba. Essas variáveis são incrementadas pela adubação potássica de forma independente da fonte aplicada.
\end{abstract}

Palavras-chave: Adubação; Épocas diferentes; Raízes; Atributos físico-químicos; Pós-colheita.

\begin{abstract}
The aim of this study was to evaluate the quality of table beet (Beta vulgaris) as a function of potassium source. The experiment was conducted at the Federal University of Viçosa - Campus Rio Paranaíba - MG. Two experiments were carried out in the summer and winter seasons and with the same experimental matrix. The sources studied were potassium chloride, potassium sulfate, and potassium nitrate. The doses of K were 60,120 , and $240 \mathrm{mg} / \mathrm{dm}^{3}$ of K. The additional treatment was the control without $\mathrm{K}$ application. The factors under study were combined in a factorial scheme $(3 \times 3)+1$ and distributed in blocks to the random with six repetitions. The quality was positively altered by fertilization with K, regardless of the applied sources. Fertilization with K resulting in higher acidity, better firmness, higher $\mathrm{L}^{*} \mathrm{~A}$ and B color intensity, and a linear increase in sucrose. After storage, these variables were reduced in roots without $\mathrm{K}$ fertilization and kept when there was fertilization. The quality of roots (soluble solids, texture, and sucrose) of plants grown in winter was higher than in summer crops, with no significant influence of the K source. After being stored, the roots of plants grown in winter showed increased concentration of sucrose, color intensity
\end{abstract}


(L*), acidity, and soluble solids as a function of doses. Thus, it is concluded that $\mathrm{K}$ sources do not have significant effects on quality at harvest and after storage in table beets. These variables are increased by potassium fertilization independently of the applied source.

Keywords: Fertilization; Different seasons; Roots; Physical-chemical attributes; Post-harvest.

\section{Resumen}

El objetivo de este estudio fue evaluar la calidad de la remolacha de mesa (Beta vulgaris) en función a fuentes de potasio. El experimento se realizó en la Universidad Federal de Viçosa - Campus Rio Paranaíba - MG. Se realizaron dos experimentos en las temporadas de verano e invierno y con la misma matriz experimental. Las fuentes estudiadas fueron cloruro de potasio, sulfato de potasio y nitrato de potasio. Las dosis de K fueron 60, 120 y $240 \mathrm{mg} / \mathrm{dm}^{3} \mathrm{de} \mathrm{K}$. El tratamiento adicional fue el control sin aplicación de K. Los factores en estudio se combinaron en un esquema factorial $(3 \times 3)+1$ y se distribuyeron en bloques completos al azar con seis repeticiones. La calidad fue alterada positivamente con la fertilización con $\mathrm{K}$, independientemente de las fuentes aplicadas. La fertilización con K resultó en mayor acidez, mejor firmeza, mayor intensidad de cromática L * A y B y aumento lineal de sacarosa. Después del almacenamiento, estas variables se redujeron en las raíces sin fertilización con $\mathrm{K}$ y se mantuvieron cuando hubo fertilización. La calidad de las raíces (sólidos solubles, textura y sacarosa) de las plantas cultivadas en invierno fue mayor que en los cultivos de verano, sin influencia significativa de la fuente de K. Después de ser almacenadas, las raíces de las plantas cultivadas en invierno mostraron una mayor concentración de sacarosa, intensidad de color ( $\mathrm{L} *$ ), acidez y sólidos solubles en función a las dosis. Por tanto, se concluye que las fuentes de K no tienen efectos significativos sobre la calidad en la cosecha y en el almacenamiento en la remolacha de mesa. Estas variables aumentan con la fertilización potásica independientemente de la fuente aplicada.

Palabras clave: Fertilización; Diferentes épocas; Raíces; Atributos físico-químicos; Post-cosecha.

\section{Introdução}

Os atributos de qualidade dos produtos agrícolas representam o grau de aceitação pelo consumidor, isto consiste desde formas, cores, sabores, açúcares e minerais que interferem no valor nutricional dos produtos. A beterraba é uns dos produtos que possui alto interesse comercial, já que apresenta boas qualidades bioativas para a alimentação, além disso, é uma cultura geradora de renda para o produtor. Assim, devem-se gerenciar adubações equilibradas para seu bom desenvolvimento e diminuir as condições de estresse que prejudicam suas características físico-químicas e sua aceitação no mercado (Zhang et al., 2018; Loan \& Hoffmann, 2014; Ninfali \& Angelino, 2013; FAO, 2011).

A beterraba é uma hortaliça de grande importância no mercado brasileiro, principalmente por apresentar altos valores nutricionais na dieta do consumidor. O bom manejo agronómico da cultura desde a semeadura, nutrição equilibrada, manejo fitossanitário e boas práticas após-colheita gerenciam melhor qualidade de beterrabas ofertadas. Por isso, a adoção de tecnologias como a boa nutrição pode inferir em produtos de alta qualidade (Amorim et al., 2020; Akhiyarov et al., 2018; Silva Curvêlo et al., 2018).

A não aplicação das boas práticas previstas pelas legislações que garantem a qualidade e a segurança do alimento pode interferir nas características sensoriais do produto oferecido, os quais podem reduzir a qualidade, resultando em prejuízos monetários (Silva et al., 2020). Portanto, é necessário um gerenciamento nutricional equilibrado enfatizando a boa produtividade da cultura, a qualidade e o estado dos nutrientes no solo ao aplicar os fertilizantes (Li et al., 2019).

O potássio é um nutriente que participa na formação e a translocação de açúcares, contribui para o crescimento das raízes, aumento de tamanho e qualidade, além da maior resistência a pragas e doenças estão associadas com a nutrição potássica equilibrada (Zhang et al., 2018; Fernandes et al. 2018; Ali et al., 2018). As principais fontes solúveis de potássio (K) diferem quanto ao ânion acompanhante, o qual pode ter influência na produtividade e qualidade das raízes de beterraba.

Em condições ambientais adversas o potássio aumenta o conteúdo da agua nas beterrabas diminuindo os danos gerados pelo estresse oxidativo nos tecidos refletindo uma melhor qualidade (Aksu \& Altay, 2019). Em ambientes restritivos como os de solo salinos contribuí na absorção de cálcio gerando um desenvolvimento maior da parte aérea obtendo uma melhora na produtividade (Hussain et al., 2014). 
As características de qualidade acumuladas durante a fase de produção devem ser mantidas da colheita até o consumo das hortaliças. Assim, o armazenamento das raízes de beterraba é importante, pois, permite que o cultivo seja realizado na época do ano com temperaturas amenas e baixa precipitação pluvial. Com as condições ideais para o cultivo a produtividade e a qualidade são maiores. A fonte de K pode influenciar a produtividade e qualidade dos produtos hortícolas. Diante disso, objetivou-se determinar a qualidade da beterraba de mesa (Beta vulgaris) em função da fonte potássica do fertilizante.

\section{Material e Métodos}

Foram conduzidos dois experimentos em duas épocas de cultivo da beterraba, localizadas nas coordenadas (Latitude $19^{\circ} 12^{\prime} 49,8^{\prime \prime} \mathrm{S}$, Longitude - 46 $\left.{ }^{\circ} 13^{\prime} 55,32^{\prime \prime} \mathrm{O}\right)$. O solo utilizado no experimento foi um Latossolo Vermelho-Amarelo de textura argilosa, cujos atributos químicos são apresentados na Tabela 1.

Tabela 1 - Análise química de amostras dos solos utilizados nos experimentos.

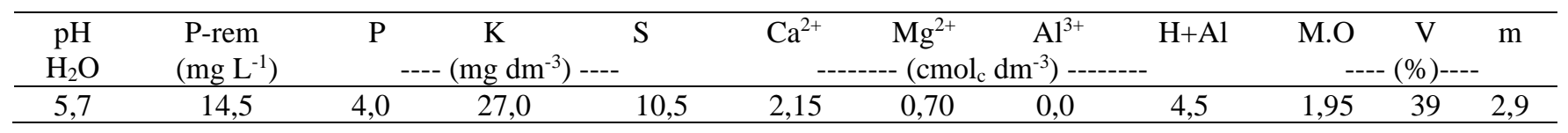

pH H $\mathrm{H}_{2} \mathrm{O}$ : Relação 1:2,5; $\mathrm{P} \mathrm{e} \mathrm{K}^{+}$: extrator Mehlich-1; S: extrator fosfato monocálcico em ácido acético; $\mathrm{Ca}^{2+}, \mathrm{Mg}^{2+}, \mathrm{Al}^{3+}$ : extrator KCl 1 mol $\mathrm{L}^{-1} ; \mathrm{H}+\mathrm{Al}$ : extrator acetato de cálcio $0,5 \mathrm{~mol} \mathrm{~L}^{-1}, \mathrm{pH} 7,0 ;$ M.O; matéria orgânica. Fonte: Autores.

Os tratamentos consistiram na combinação de dois fatores, fontes e doses. As doses de K foram de 60,120 e de 240 $\mathrm{mg} / \mathrm{dm}^{3}$ de $\mathrm{K}$, as fontes estudadas foram o cloreto de potássio $\left(60 \%\right.$ de $\left.\mathrm{K}_{2} \mathrm{O}\right)$, o sulfato de potássio $\left(50 \%\right.$ de $\left.\mathrm{K}_{2} \mathrm{O}\right)$ e o nitrato de potássio $\left(45 \%\right.$ de $\mathrm{K}_{2} \mathrm{O}$ e $12 \%$ de $\mathrm{N}$ ). O tratamento adicional foi a testemunha sem aplicação de K. Os fatores em estudo foram combinados em esquema fatorial $(3 \times 3)+1$ e distribuídos em blocos ao acaso com seis repetições.

Cada parcela consistiu de um vaso de $150 \mathrm{dm}^{3}$ preenchido com solo tamisado e homogeneizado. Em cada vaso 60 sementes (glomérulos) de beterraba da variedade Boro foram semeadas. Quando as plantas apresentaram quatro folhas foi realizado o desbaste para que remanescessem 20 plantas por vaso, o que equivalente a 40 plantas por $\mathrm{m}^{2}$, comum em cultivos comerciais.

O solo foi corrigido com calcário para que a saturação por bases atingisse $70 \%$. Para suprir cálcio e enxofre foi utilizado gesso agrícola na dose de $500 \mathrm{mg} / \mathrm{dm}^{3}$ (equivalente a $1 \mathrm{t} / \mathrm{ha}$ ). O fósforo $\left(480 \mathrm{mg} / \mathrm{dm}^{3}\right.$ de P) foi incorporado no solo da camada de $0-20 \mathrm{~cm}$ do vaso e a dose foi definida de acordo com o P-remanescente do mesmo utilizando-se a fonte superfosfato triplo (Alvarez V. et al., 2000). A aplicação do $\mathrm{N}$ foi parcelada: $50 \mathrm{mg} / \mathrm{dm}^{3}$ na semeadura e uma cobertura de 30 $\mathrm{mg} / \mathrm{dm}^{3}$. As correções com B, Cu e $\mathrm{Zn}$ foram realizadas com fontes solúveis para atingir disponibilidades correspondentes às classes de alta fertilidade apresentadas por Ribeiro et al. (1999). O K, de acordo com dose e fonte de cada tratamento, foi aplicado incorporado ao solo $(0-20 \mathrm{~cm})$ antes da semeadura. A dose de $\mathrm{N}$ de cada tratamento foi nivelada com o uso de nitrato de amônio (33\% de N).

A irrigação e o manejo fitossanitário foram realizados de maneira manual periodicamente para eliminar interferências bióticas e estresse hídrico sobre as plantas.

Os parâmetros qualitativos das raízes da beterraba foram determinados no Laboratório de Solos e Alimentos da UFVCRP. Uma parte das amostras foram acondicionadas em sacos devidamente identificados sem serem lavadas e em seguida armazenadas em câmara fria a uma temperatura de $5 \pm 1{ }^{\circ} \mathrm{C}$ e UR de $90 \pm 5 \%$ durante 150 dias para posterior analises póscolheita. 
A medida da firmeza foi feita na região equatorial das raízes das beterrabas, foi utilizado o texturômetro digital TDBC-200 com ponteira de $8 \mathrm{~mm}$ de diâmetro, avaliando-se duas repetições para cada raiz. Os resultados da firmeza foram expressos em Newton.

A coloração foi determinada através da medição em dois pontos internos da parte equatorial de cada raiz, utilizandose um colorímetro digital Deltavista (faixa espectral $400 \mathrm{~nm}$ a $700 \mathrm{~nm}$ ) e os valores expressos em L*, A* e B*. Onde L*, indica valores de luminosidade $(0 \%=$ negro e $100 \%=$ branco $), \mathrm{A}^{*}$ é mensurável em termos de intensidade das cores vermelho e verde, e a coordenada B* está relacionada com a intensidade de amarelo e do azul (AOAC, 1997).

Para determinação do $\mathrm{pH}$ e da acidez titulável, foram pesadas $5 \mathrm{~g}$ do extrato aquoso da beterraba, diluída em $50 \mathrm{~mL}$ de água destilada e com auxílio de um potenciômetro digital foi obtida o pH. Para acidez foi feita a titulação potenciométrica com solução de $\mathrm{NaOH}$ al $0,01 \mathrm{~mol} / \mathrm{L}$ e uso do indicador de $\mathrm{pH}$ até 8,1 . Os resultados foram expressos em concentração porcentual de ácido cítrico.

A obtenção de teor de sólidos solúveis totais foi feita com um refratômetro digital portátil RTD-95. Para tal, gotas do suco extraído das raízes foram aplicadas sobre a lente do aparelho e os resultados foram expressos em ${ }^{\circ}$ Brix.

Os açucares (glucose, frutose, sacarose) foram quantificados em amostra líquida. Para isso uma curva de resposta do sinal analítico contra concentração dos padrões de sacarose, glicose e frutose foi ajustada para verificar a linearidade do detector no intervalo de concentração. As massas de padrão de sacarose, glicose e frutose foram pesadas e diluídas em água relação massa/massa (m/m) - e, após filtração, foram analisadas por HPLC-R (Santos et al. 2006).

Os dados obtidos foram submetidos à verificação da normalidade e homogeneidade das variâncias. Posteriormente os dados foram submetidos à análise de variância (ANOVA) e realizou-se análise de regressão para as doses de K. As médias das fontes foram comparadas pelo teste SNK. Foi utilizado nas análises estatísticas o Software em planilha eletrônica SPEED Stat (Carvalho \& Mendes, 2020) e adotada a significância de 5\%.

\section{Resultados}

No cultivo de verão a firmeza das raízes de beterrabas, antes do armazenamento, foi incrementada pela adubação potássica até a dose de $218 \mathrm{mg} / \mathrm{dm}^{3}$, sem efeito da fonte de K (Figura 1). Após o armazenamento essa variável não foi alterada pelos fatores em estudo. A resistência das raízes cultivadas no inverno não foi alterada pelos fatores em estudo antes do armazenamento. Após o armazenamento, independente das fontes utilizadas, a resistência das raízes foi mantida pela adubação potássica. 
Figura 1. Textura das raízes beterrabas em função a fontes e doses de potássio em duas épocas de cultivo (verão e inverno). UFV, Rio Paranaíba - MG (2020).
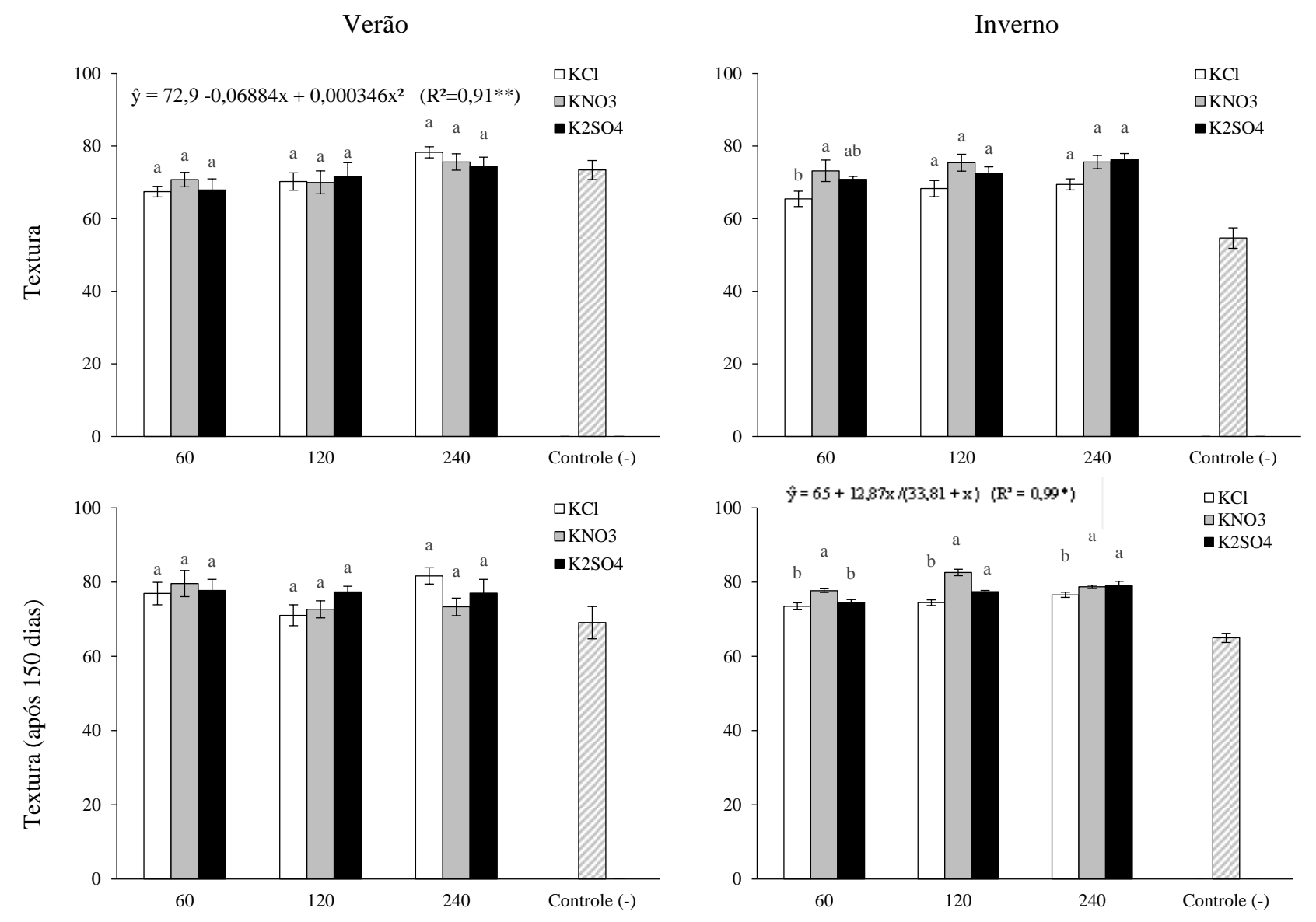

Doses de K (mg/dm $)$

Doses de K $\left(\mathrm{mg} / \mathrm{dm}^{3}\right)$

Fonte: Autores.

A maior intensidade ou luminosidade da cor ( $\mathrm{L}^{*}$ ) foi obtida quando as plantas foram adubadas com $240 \mathrm{mg} / \mathrm{dm}^{3} \mathrm{de} \mathrm{K}$ via $\mathrm{KNO}_{3}$. Após o armazenamento a luminosidade da cor foi maior quando a fonte de $\mathrm{K}$ empregada foi o $\mathrm{KCl}$ com a aplicação de $240 \mathrm{mg} / \mathrm{dm}^{3}$ de $\mathrm{K}$. As raízes obtidas do cultivo do inverno apresentaram luminosidade da cor ( $\mathrm{L}^{*}$ ) semelhantes, independentemente da dose ou fonte de $\mathrm{K}$ aplicada no solo (Figura 2). Posterior ao armazenamento, os maiores valores de $\mathrm{L}^{*}$ foram alcançados com a dose estimada de $176 \mathrm{mg} / \mathrm{dm}^{3} \mathrm{de} \mathrm{K}$.

A máxima absorbância cromática (A) nas raízes produzidos em verão foi obtida com $74,39 \mathrm{mg} / \mathrm{dm}^{3} \mathrm{de} \mathrm{K}$ independente da fonte utilizada. Após o armazenamento essa variável não foi alterada pelos fatores em estudo. As raízes obtidas do cultivo do inverno apresentaram intensidade cromática (A) na colheita e após o armazenamento inalterada ao fornecimento de $\mathrm{K}$.

Antes do armazenamento das raízes colhidas do cultivo de verão a coordenada cromática (B) foi incrementada até a dose de $74 \mathrm{mg} / \mathrm{dm}^{3}$ de $\mathrm{K}$ independente das fontes. Essa variável não foi alterada pelos tratamentos após o armazenamento. A coordenada cromática (B) das raízes colhidas no inverno não foi alterada por fontes ou doses após a colheita ou armazenamento. 
Figura 2. Intensidade da $\operatorname{Cor} L, A$ e $B$ das raízes de beterrabas na colheita e pós-colheita em função a fontes e doses de potássio em duas épocas de cultivo (verão e inverno). UFV, Rio Paranaíba - MG (2020).

Verão
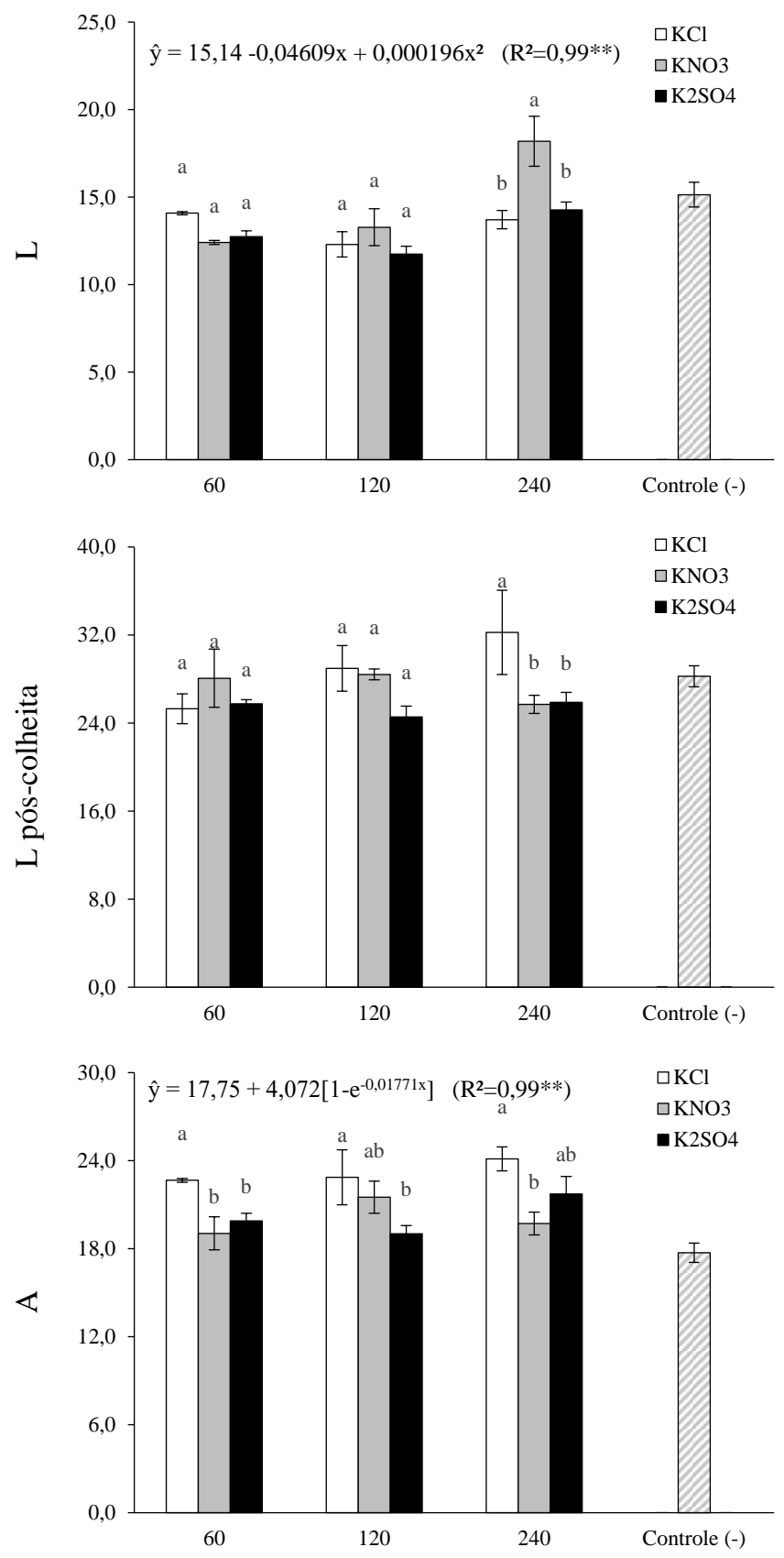

Inverno
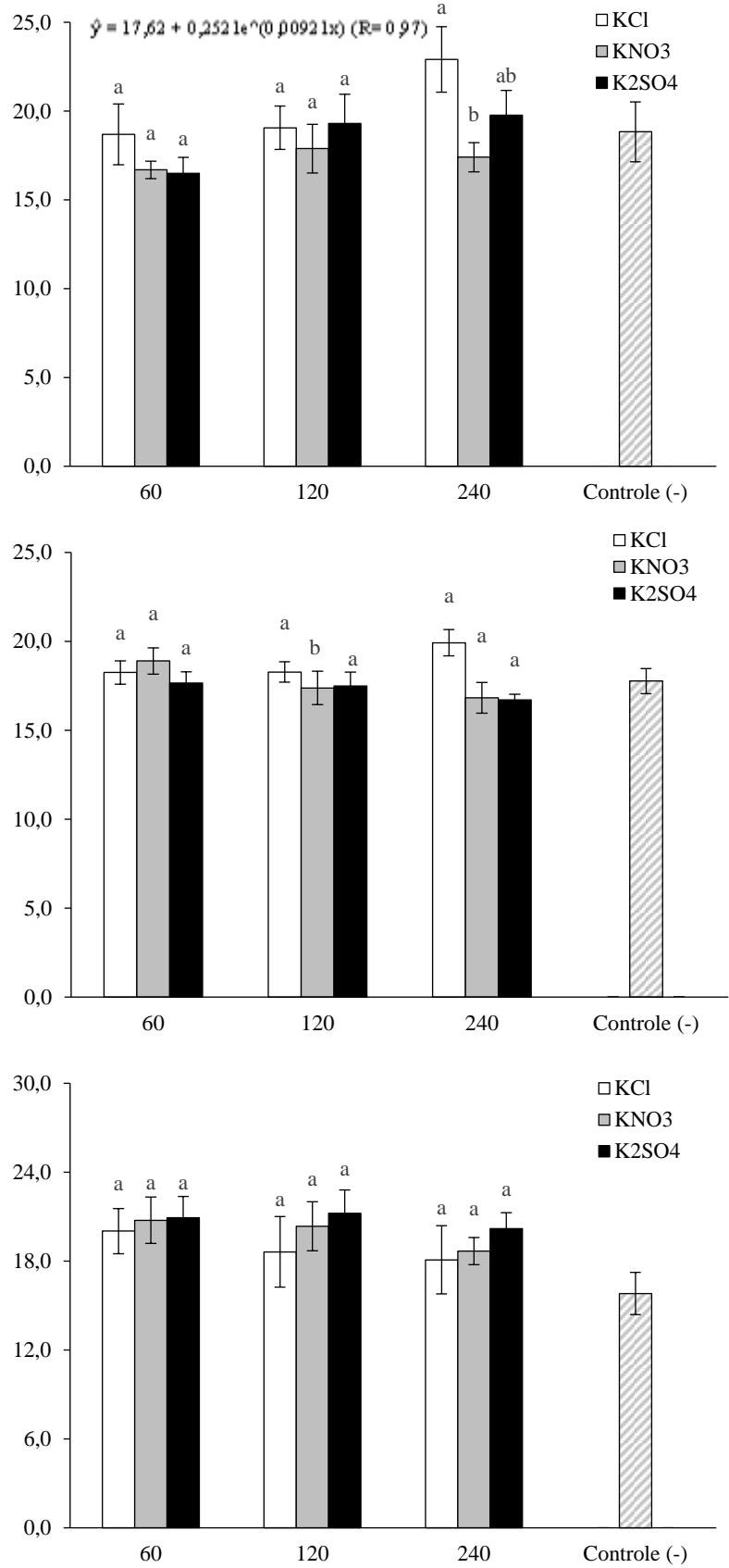

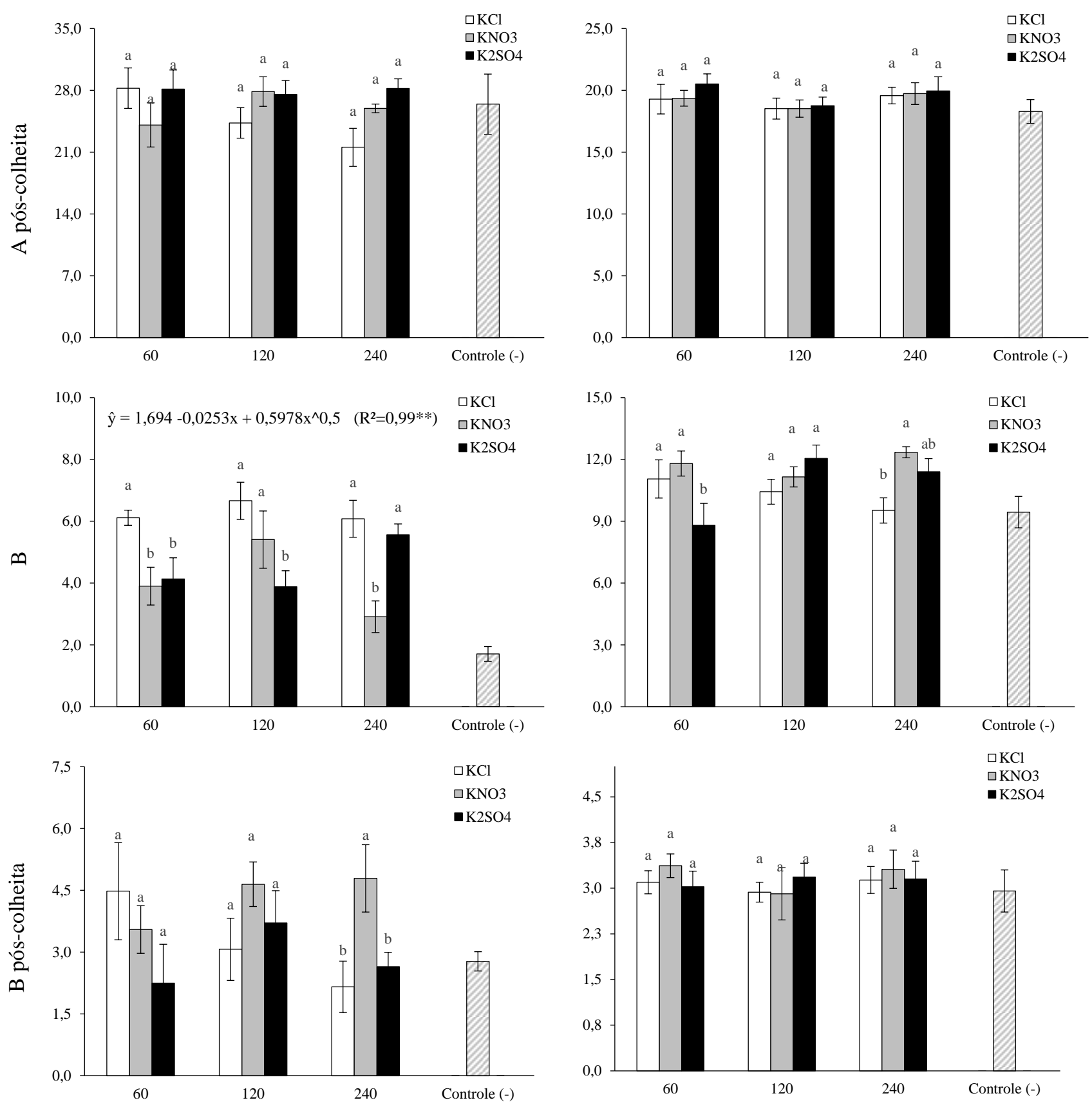

Doses de K $\left(\mathrm{mg} / \mathrm{dm}^{3}\right)$

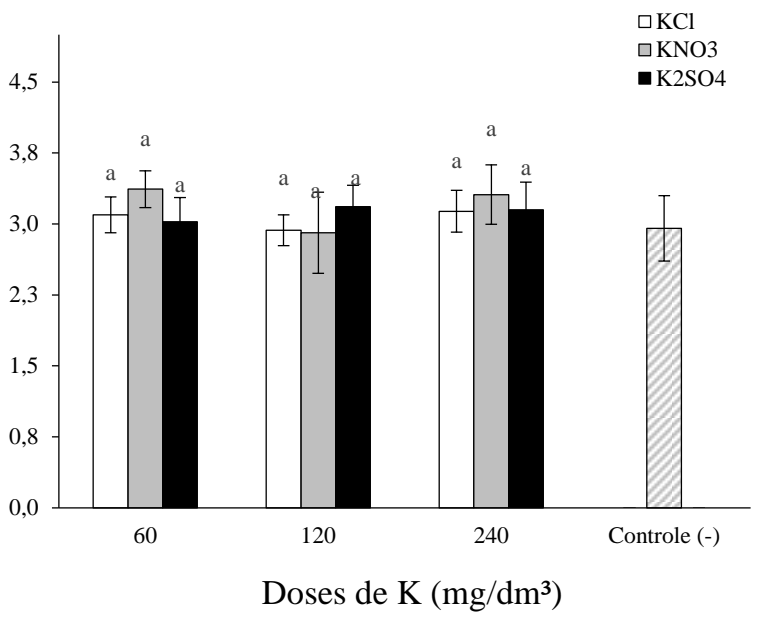

Fonte: Autores.

A acidez do suco extraído das raízes cultivadas no verão antes do armazenamento foi alterada quando empregadas as fontes $\mathrm{KCl}$ e $\mathrm{KNO}_{3}$. Após o armazenamento, a acidez foi alterada apenas quando a fonte foi o $\mathrm{KCl}$ aplicado nas doses de 120 ou de $240 \mathrm{mg} / \mathrm{dm}^{3}$ de $\mathrm{K}$. As raízes cultivadas no período de inverno não tiveram a acidez alterada pela fonte ou dose de $\mathrm{K}$. Depois de serem armazenadas as fontes de $\mathrm{K}$ não alteraram a acidez das raízes, mas a resposta foi linear em função das doses de K (Figura 3). 
Figura 3. Acidez total das raízes de beterrabas na colheita e pós-colheita em função a fontes e doses de potássio em duas épocas de cultivo (verão e inverno). UFV, Rio Paranaíba - MG (2020).
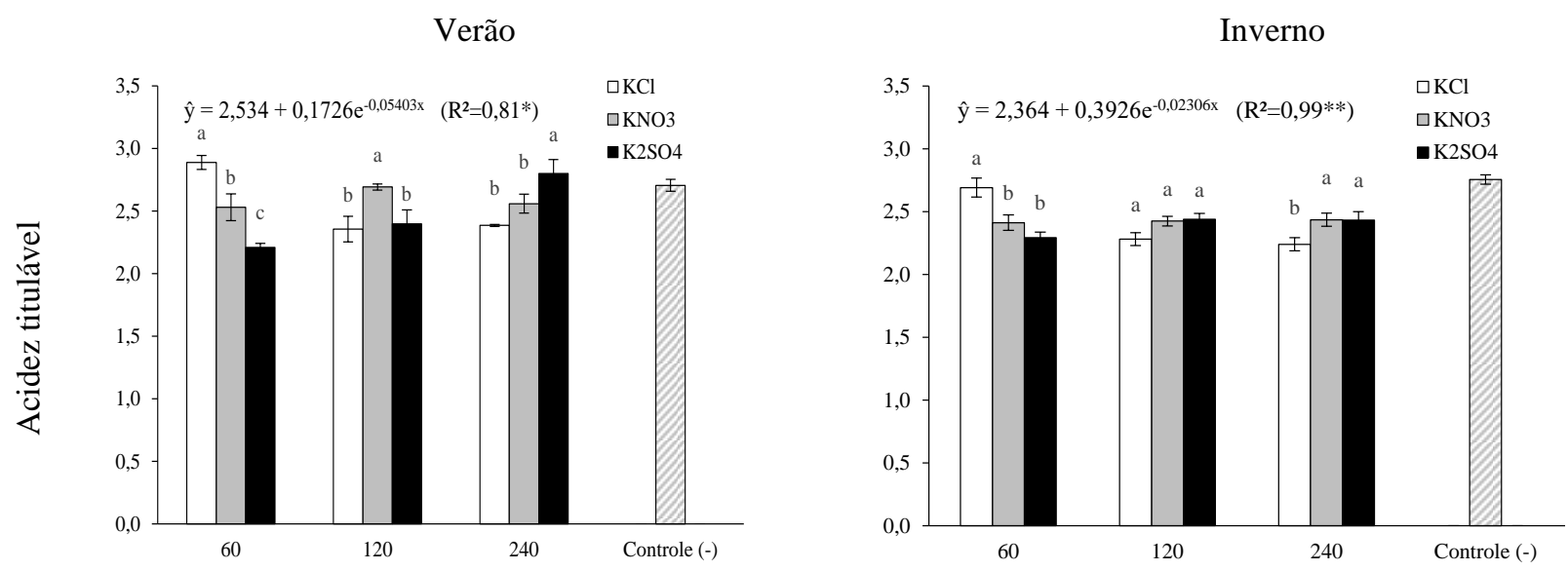

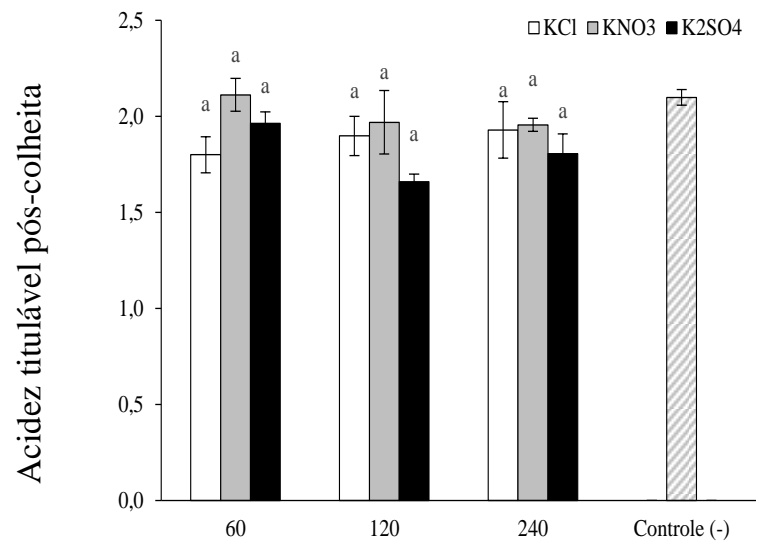

Doses de $\mathrm{K}\left(\mathrm{mg} / \mathrm{dm}^{3}\right)$

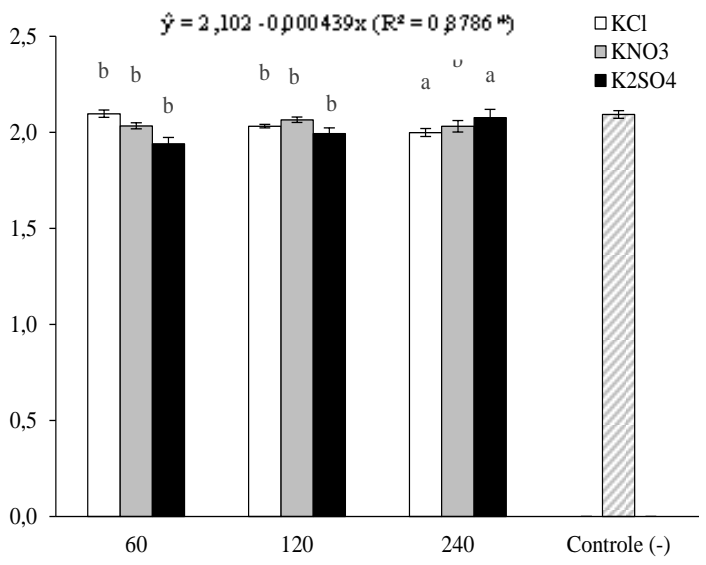

Doses de $\mathrm{K}\left(\mathrm{mg} / \mathrm{dm}^{3}\right)$

Fonte: Autores.

Os sólidos solúveis totais das raízes de beterraba cultivadas no verão não foram alterados pelos tratamentos (Figura 4). Após armazenamento, a combinação da dose de $120 \mathrm{mg} / \mathrm{dm}^{3}$ de $\mathrm{K}$ com a fonte $\mathrm{K}_{2} \mathrm{SO}_{4}$ proporcionou o maior valor de sólidos solúveis totais ( ${ }^{\circ}$ Brix). No cultivo de inverno os valores de sólidos solúveis foram maiores que os obtidos nas raízes cultivadas no verão e sem efeito consistente da fonte de K. Não obstante, depois de serem armazenados houve alterações do teor de sólidos solúveis das raízes de beterrabas como respostas as fontes e doses de K. As raízes que receberam fornecimento de $\mathrm{K}$ da fonte $\mathrm{KNO}_{3}$ apresentaram maior teor de sólidos solúveis após armazenamento em comparação ao outras fontes (KCl e $\mathrm{K}_{2} \mathrm{SO}_{4}$ ). Para alcance do máximo sólidos solúveis foram necessários $135 \mathrm{mg} / \mathrm{dm}^{3} \mathrm{de} \mathrm{K}$.

O principal açúcar solúvel detectado foi a sacarose que foi incrementada até a dose de $125 \mathrm{mg} / \mathrm{dm}^{3} \mathrm{de} \mathrm{K}$. As maiores percentagens de sacarose no cultivo de verão foram associadas ao uso da fonte $\mathrm{KNO}_{3}$. (Figura 4). Após 150 dias de armazenamento em câmara fria a percentagem de sacarose não dependeu dos tratamentos.

No cultivo de inverno, similar ao cultivo de verão, o principal açúcar solúvel foi a sacarose e as quantidades de glicose e de frutose foram não detectáveis. A concentração de sacarose foi maior nas raízes obtidas do cultivo do inverno, em comparação as cultivadas no verão. Após o armazenamento o açúcar solúvel apresentado foi à sacarose, as fontes de K não alteraram o teor da sacarose, não obstante a sacarose foi aumentada de maneira linear com os níveis de $\mathrm{K}$ fornecidas. 
Figura 4. Sólidos solúveis e sacarose das raízes de beterrabas na colheita e após 150 dias de armazenamento em câmara fria em função a fontes e doses de potássio em duas épocas de cultivo (verão e inverno). UFV, Rio Paranaíba - MG (2020).

Verão
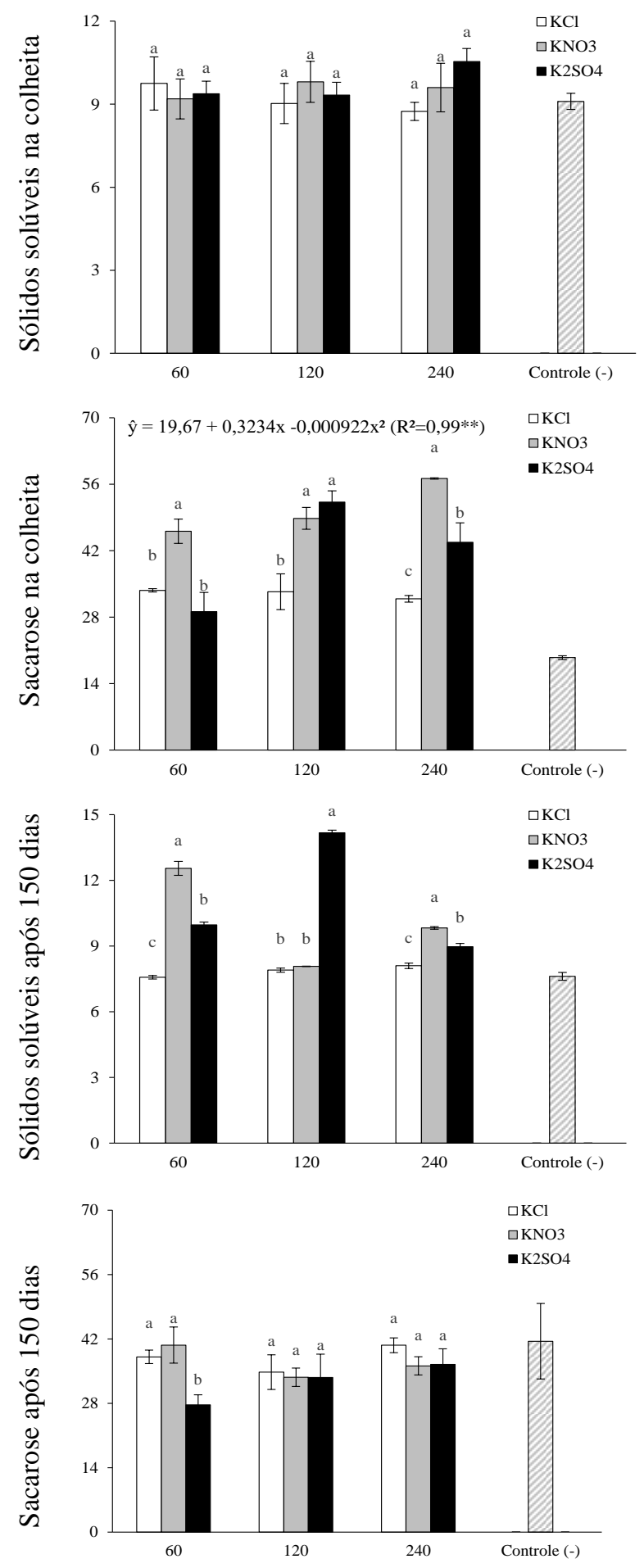

Doses de K $\left(\mathrm{mg} / \mathrm{dm}^{3}\right)$
Inverno
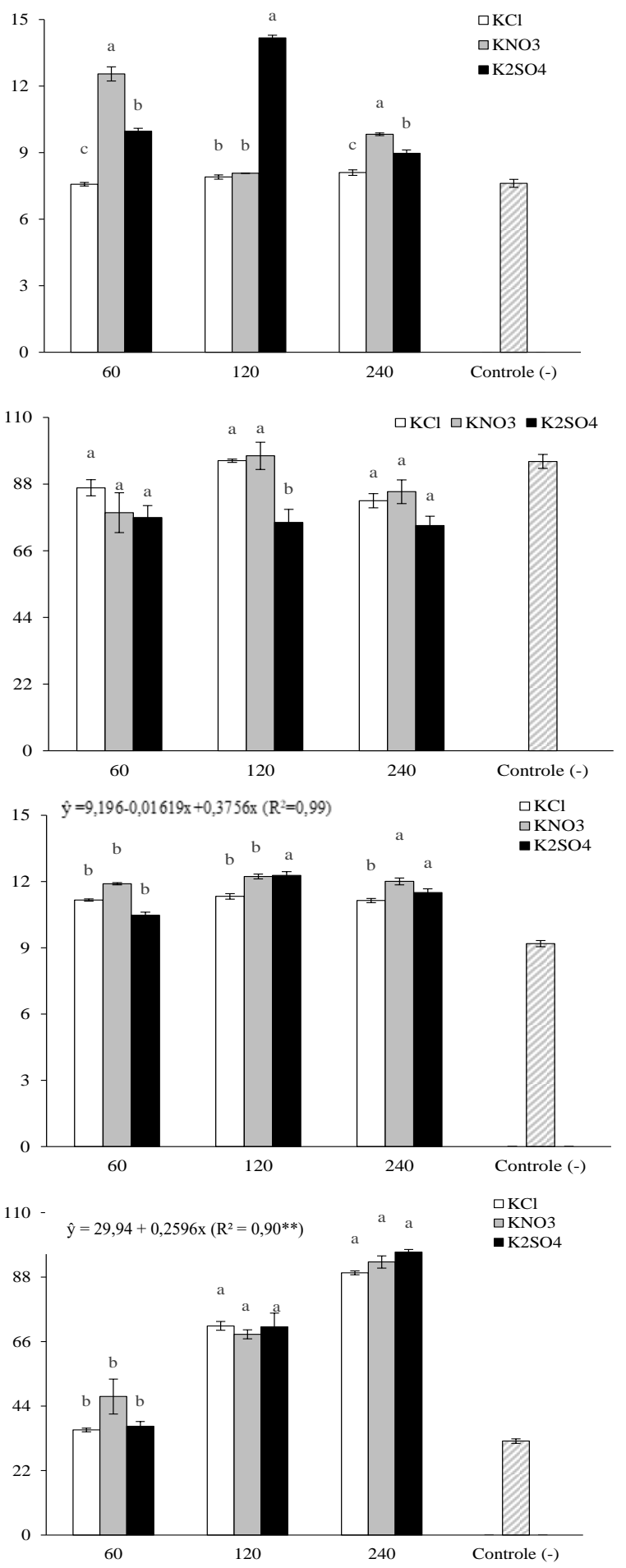

Doses de K $\left(\mathrm{mg} / \mathrm{dm}^{3}\right)$

Fonte: Autores. 


\section{Discussão}

$\mathrm{O}$ aumento da firmeza das raízes no verão para doses de $240 \mathrm{mg} / \mathrm{dm}^{3} \mathrm{de}_{2} \mathrm{O}$ na fonte de $\mathrm{KCl}$ é devido provavelmente ao aproveitamento do íon $\mathrm{Cl}$ que está associado ao metabolismo da água, transpiração e atividade fotossintética das plantas. Assim, após colheita, a respiração total pode ser reduzida por meio da inibição da respiração da via do citocromo e biossíntese de etileno (Guo et al., 2014; Taiz \& Zeiger, 2013).

No cultivo de inverno, os tratamentos não influenciaram a firmeza das raízes. Entretanto, as médias foram maiores que as obtidas das raízes cultivadas no verão. A beterraba tem melhores condições para seu crescimento com temperaturas médias de 10 a $20{ }^{\circ} \mathrm{C}$ e com bom suprimento hídrico (Puiatti \& Finger, 2005; Coutinho et al., 2018). Como no verão as temperaturas médias durante o cultivo variaram de 21,1 a $22,6^{\circ} \mathrm{C}$ à planta possivelmente sofreu estresse térmico.

Após o armazenamento das beterrabas produzidas no verão não houve diferença entre os tratamentos para variáveis de qualidade. A perda de firmeza com o armazenamento é devido ao consumo das reservas para manutenção vegetal, que culminam com enfraquecimento da parede celular (Mendonça et al., 2007; Drake et al., 2004). Após o armazenamento das raízes colhidas no inverno houve diminuição da firmeza, quando não se realizou adubação potássica. Essa foi mantida quando realizada adubação, independente da fonte. A deficiência de $\mathrm{K}$ aumenta a taxa de respiração e, com isso, mais energia é necessária para esta função, o que culmina na redução do tempo de armazenamento (Pettigrew, 2008).

As raízes de beterrabas produzidas com adubação de $60 \mathrm{mg} / \mathrm{dm}^{3}$ de $\mathrm{K}$ via $\mathrm{KCl}$ apresentaram maior acidez em comparação as doses maiores do nutriente. Isso pode ter ocorrido porque o íon $\mathrm{Cl}$ em elevadas concentrações influencia negativamente as enzimas responsável da formação do ácido cítrico (Argentel et al., 2009). Entretanto, com $\mathrm{KNO}_{3}$ houve maior acidez com $120 \mathrm{mg} / \mathrm{dm}^{3}$, justificando-se que a planta assimilou melhor o $\mathrm{N}$ nessa dose. As plantas bem supridas com $\mathrm{K}$ estão aptas para absorver mais nitrogênio aumentando a rapidez da convenção do $\mathrm{N}$ à proteína. Assim, baixo suprimento de $\mathrm{K}$ restringe o transporte adequado de $\mathrm{NO}_{3}$ e inibe a formação das proteínas, levando ao acúmulo na planta de nitrato-N e amino- $\mathrm{N}$ solúvel (Römheld \& Kirkby, 2010).

A adubação com $\mathrm{K}_{2} \mathrm{SO}_{4}$ resultou em aumento da acidez em função das doses de K. Isso ratifica a importância do íon acompanhante (S) no metabolismo das plantas como potencial defensor contra estresse (Rausch \& Wachter, 2005). O fornecimento adequado de K eleva o teor de ácido ascórbico, aumentando assim a acidez titulável (Chitarra \& Chitarra, 2005). Quanto maior a concentração vacuolar de cátions, maior será concentração de ácidos orgânicos Carneiro et al. (2018).

Os ácidos orgânicos após armazenamento de frutos de maçãs foram menores quando as plantas foram subnutridas em K (Hunsche et al., 2003). Resultado similar foi observado em beterrabas, com redução dos teores dos ácidos, o que pode ser explicado pela maior taxa metabólica das raízes durante o armazenamento.

Com relação aos atributos de coloração das raízes de beterraba, foi observado que na leitura do fator luminosidade (L*), em plantas cultivadas no verão e adubadas com $240 \mathrm{mg} / \mathrm{dm}^{3}$ de $\mathrm{K}$ fornecido com $\mathrm{KNO}_{3}$ a contribuição do íon acompanhante no aumento de pigmentos e propriedades antioxidantes nas raízes de beterraba. Não tem registros de pesquisas da influência de fontes de $\mathrm{K}$ na cor de raízes de beterraba. Em outras culturas, independente das fontes, o $\mathrm{K}$ melhora a coloração vermelha (Hunsche et al., 2003).

Após a colheita das raízes de beterrabas cultivadas no inverno, não houve alteração na variável ( $\left.L^{*}\right)$. Entretanto, depois do armazenamento dessas raízes, houve interferências das doses de $\mathrm{K}$, a qual indica a intensificação da cor vermelho devido ao aumento de betanina nas raízes (Gonçalves et al., 2015).

$\mathrm{O}$ incremento da intensidade de cor vermelha (A) nas raízes de beterraba cultivadas no verão em função de doses de $\mathrm{K}$ pode ser atribuído à maior estabilidade do complexo de proteínas a atividade das enzimáticas antiestresse. A betaleína, pigmento menos sensível ao calor é incrementada pelo K (Chen et al., 2018; Barrett et al., 2010), o que pode melhor a intensidade da cor vermelha. 
Os valores de (B) não foram modificados nas raízes cultivadas no inverno, logo após a colheita ou após o armazenamento. Entretanto, foi incrementada pelas doses de $\mathrm{K}$ nas raízes cultivadas no verão. O aumento dos valores de B indica maior contribuição da cor amarela, a qual é devida a presença de carotenoides que exercem o papel de proteger as raízes das beterrabas em situações adversas de temperaturas e luz (Barrett et al., 2010).

A falta de resposta aos tratamentos sobre os sólidos solúveis nas raízes cultivadas no verão pode ser devido ao estresse de térmico a que as plantas foram submetidas. O potássio é um nutriente que normalmente incrementa o acúmulo de açúcares, ácidos orgânicos e íons inorgânicos, os quais elevam o ${ }^{\circ}$ Brix, a capacidade antioxidante e a firmeza (Preciado-Rangel et al., 2018). Quando a planta tem algum tipo de estresse às atividades enzimáticas são afetadas e em vez de gerar metabolitos primários como "açucares", há investimento nos metabólitos secundários como mecanismo de defesa ante os fatores adversos (Amaral et al., 2020; Zhang et al., 2018; Taiz \& Zeiger, 2013).

O maior acúmulo de sólidos solúveis nas raízes cultivadas no inverno comparado às de verão foi provavelmente devido ao menor estresse térmico e, por conseguinte, maior aproveitamento dos demais nutrientes fornecidos como o N, Ca e S. A adubação nitrogenada em beterraba incrementa os sólidos solúveis de forma quadrática (Aquino et al., 2006). A adubação potássica melhorou a eficiências nas funções bioquímica dos nutrientes, com possível maior atividade da redutase do nitrato nas folhas, e das enzimas antioxidantes, o que proporciona maior acúmulo de carboidratos e, por consequência, maior ${ }^{\circ}$ brix (Souza et al., 2020; Lima et al., 2020).

Após armazenamento houve redução do ${ }^{\circ}$ Brix, independente das fontes e das doses de $\mathrm{K}$ empregadas no cultivo da beterraba. Os açúcares têm funções estruturais ou como substratos respiratórios na geração de energia e intermediários metabólicos. Além disso, os açúcares promovem a expressão de enzimas em conexão com a biossíntese, utilização e armazenamento de reservas (amido, lipídios e proteínas) (Yu, 1999). O consumo dos açúcares para manutenção das funções vitais durante o armazenamento explica a redução do obrix. Após o armazenamento das raízes produzidas no cultivo de inverno com adubação de $\mathrm{KNO}_{3}$ houve incremento dos sólidos solúveis, fato atribuído provavelmente ao $\mathrm{N}$ melhorar a concentração de sacarose nas raízes no papel estrutural da composição de aminoácidos (Taiz \& Zeiger, 2013). A resposta às doses de K evidenciou a importância desse elemento na manutenção das atividades enzimáticas e produção de açúcar (Lester et al., 2005; Zhang et al., 2018).

A presença de sacarose no suco das raízes da beterraba não foi alterada pelas fontes de K. Entretanto, houve incremento quadrático em função das doses até $175 \mathrm{mg} / \mathrm{dm}^{3}$ de $\mathrm{K}$. Essa diferença com a testemunha deve-se ao papel do K em acrescentar a reserva de carboidratos, amenizar o estresse advindo da alta temperatura e concentrar mais sacarose (Zheng et al., 2016).

Após o armazenamento as concentrações de sacarose foram similares as do pré-armazenamento, enquanto que a frutose não detectável (antes do armazenamento) foi presente em baixas concentrações depois do armazenamento. Essas alterações não foram influenciadas pelas doses ou fontes de K empregadas no cultivo. As alterações são explicadas pela quebra dos açúcares (sacarose) e ácidos orgânicos durante a respiração dos produtos armazenados (Mahmood \& Murdoch, 2017; Taiz $\&$ Zeiger, 2013). O teor de sacarose após armazenamento das beterrabas produzidas no inverno foi incrementado pelas doses de K. O fornecimento adequado de potássio interfere em muitas enzimas envolvidas na formação e translocação de carboidratos e, com isso, as atividades bioquímicas são otimizadas (Taiz \& Zeiger, 2013).

\section{Conclusões}

As fontes de $\mathrm{K}$ não apresentaram efeitos significativos sobre a qualidade na colheita e após o armazenamento na beterraba. Essas variáveis são incrementadas pela adubação potássica de forma independente da fonte aplicada. 
Raízes de beterraba produzidas no cultivo de inverno apresentaram maior qualidade do que as produzidas no verão, independentemente da fonte de $\mathrm{K}$.

\section{Agradecimentos}

Ao CNPq - Conselho Nacional de Desenvolvimento Científico e Tecnológico, CAPES - Coordenação de Aperfeiçoamento de Pessoal de Nível Superior e FAPEMIG - Fundação de Amparo à Pesquisa do Estado de Minas Gerais pelo apoio financeiro à pesquisa.

\section{Referências}

Akhiyarov, B. G., Ismagilov, R. R., Islamgulov, D. R., Kuznetsov, I. Y., Akhiyarova, L. M., Abdulvaleev, R. R., Sergeev, V. S. (2018). Yield and quality of table beet depending on cultivation technology elements. Journal of engineering and applied sciences, 13(S11), 8752-8759.

Aksu, G., \& Altay, H. (2020). The effects of potassium applications on drought stress in sugar beet. Sugar Tech, 22(6), 1092-1102.

Ali, A., Khan, I. U., Jan, M., Khan, H. A., Hussain, S., Nisar, M., Yun, D. J. (2018). The high-affinity potassium transporter EpHKT1; 2 from the extremophile Eutrema parvula mediates salt tolerance. Frontiers in plant science, 9, 1108.

Alvarez, V. H., Novais, R. F., Dias, L. E., Oliveira, J.A. (2000). Determinação e uso do fósforo remanescente. Boletim Informativo da Sociedade Brasileira de Ciência do Solo, Viçosa, v.25, n.1, p.27-32.

Amaral, C. L., Santos, J., Portugal, C. R. S., Braga, A. F.; Alves, P. L. C. A. (2020). Growth of Vernonia ferruginea Seedlings Submitted to Thermal Stress. Planta Daninha, v. 38.

Amorim, D. J., de Sousa Ferreira, L., de Sousa, J. R., Almeida, E. I. B., Araújo, J. B., Téllez, H. O., Silva Sousa, W. (2020). Aspectos da comercialização e perdas pós-colheita de beterraba em diferentes segmentos varejistas. Research, Society and Development, 9(10), e349108191-e349108191.

AOAC. (Association of Official Analytical). Official methods of analysis. (1995). 16.ed. Washington: AOAC.

Aquino, L. A., Puiatti, M., Pereira, P. R., Pereira, F. H., Ladeira, I. R., Castro, M. R. (2006). Produtividade, qualidade e estado nutricional da beterraba de mesa em função de doses de nitrogênio. Horticultura brasileira, 24, 199-203.

Argentel, L., López, R. C., Fonseca, I., Girón, R., Gómez, E., González, L. M., López Aguilar, D. R. (2009). Contenido de clorofila e iones en la variedad de trigo harinero Cuba-C-204 en condiciones de estrés salino. Cultivos Tropicales, 30(4), 00-00.

Barrett, D. M., Beaulieu, J. C., Shewfelt, R. (2010). Color, flavor, texture, and nutritional quality of fresh-cut fruits and vegetables: desirable levels, instrumental and sensory measurement, and the effects of processing. Critical reviews in food science and nutrition, v. 50, n. 5, p. 369-389.

Carneiro, M. A., Lima, A. M. N., Cavalcante, Í. H. L., Sousa, K. D., Oldoni, F. C. A., Barbosa, K. D. S. (2018). Production and quality of mango fruits cv. Tommy atkins fertigated with potassium in semi-arid region. Revista Brasileira de Fruticultura, v. 40, n. 5.

Carvalho, A. M. X., Mendes, F. Q., Mendes, F. Q., Tavares, L. T. (2020). SPEED Stat: A free, intuitive, and minimalist spreadsheet program for statistical analyses of experiments. Crop Breeding and Applied Biotechnology, 20(3):e327420312.

Chen, Z., Tao, X., Khan, A., Tan, D.K., Luo, H. (2018). Biomass accumulation, photosynthetic traits and root development of cotton as affected by irrigation and nitrogen-fertilization. Frontiers in Plant Science, v. 9, p. 173.

Chitarra, M. I. F., Chitarra, A. B. (2005). Pós-colheita de frutos e hortaliças: fisiologia e manuseio. 2. ed. rev. e ampl. Lavras: UFLA.

Coutinho, P. W., Echer, M. M., Oliveira, P. S., Dalastra, G. M., Cadorin, D. A., Vanelli, J. (2018). Productivity and Qualitative Characteristics of Varieties of Beets. Journal of Agricultural Science, v. 10, n. 6.

Drake, S. R., Mielke, E. A., Elfving, D. C. (2004). Maturity and Storage Quality ofConcorde'Pears. HortTechnology, v. 14, n. 2, p. $250-256$.

FAO (Organización de las Naciones Unidas para la Agricultura y la Alimentación). (2011). Global food losses and food waste - Extent, causes and prevention. Rome// www.fao.org/docrep/005/s8630s/s8630s00.htm.

Fernandes, M. S., De Souza, S. R., Santos, L. (2018). Nutrição Mineral de Plantas. 2. Ed. Viçosa, MG. Sociedade Brasileira de Ciência do Solo. 670 p.

Gonçalves, C. A., Lima, L. C., Lopes, P. S., Prado, ME. (2006). Caracterização física, físico-química, enzimática e de parede celular em diferentes estádios de desenvolvimento da fruta de figueira. Food Science and Technology, v. 26, n. 1, p. 220-229.

Guo, Q., Wu, B., Peng, X., Wang, J., Li, Q., Jin, J., Ha, Y. (2014). Effects of chlorine dioxide treatment on respiration rate and ethylene synthesis of postharvest tomato fruit. Postharvest Biology and Technology, v. 93, p. 9-14.

Hussain, Z., Khattak, R. A., Irshad, M., \& Mahmood, Q. (2014). Sugar beet (B eta vulgaris L.) response to diammonium phosphate and potassium sulphate under saline-sodic conditions. Soil use and management, v. 30, p. 320-327. 
Lester, G. E., Jifon, J. L., Rogers, G. (2005). Supplemental foliar potassium applications during muskmelon fruit development can improve fruit quality, ascorbic acid, and beta-carotene contents. Journal of the American Society for Horticultural Science, v. 130, n. 4, p. 649-653.

Li, Z., Zhang, R., Xia, S., Wang, L., Liu, C., Zhang, R., Liu, Y. (2019). Interactions between N, P and K fertilizers affect the environment and the yield and quality of satsumas. Global Ecology and Conservation, 19, e00663.

Lima, G. S., Pinheiro, F. W., Gheyi, H. R., Soares, L. A., Silva, S. D. (2020). Crescimento e qualidade pó-colheita de Frutos de Acerola irrigada com águas salinas e adubação Potássica. Revista Caatinga, v. 33, n. 3, p. 775-784.

Loel, J.; Hoffmann, C. M. (2014). Importance of growth stage and weather conditions for the winter hardiness of autumn sown sugar beet. Field Crops Research, v. 162, p. 70-76.

Mahmood, S. A., \& Murdoch, A. J. 2017. Within-field variations in sugar beet yield and quality and their correlation with environmental variables in the East of England. European journal of agronomy, 89, 75-87.

Mendonça, R. D., Ferreira, K. S., Souza, L M. D., Marinho, C.S., Teixeira, S.L. 2007. Caracteristicas físicas e químicas de goiabas' Cortibel 1'e'Cortibel 4'armazenadas em condições ambientais. Bragantia, v. 66, n. 4, p. 685-692.

Ninfali, P.; Angelino, D. (2013). Nutritional and functional potential of Beta vulgaris cicla and rubra. Fitoterapia, v. 89, p. 188-199.

Pauiatti, M.; Finger, F. L. (2005). Fatores climáticos. FONTES, PCR Olericultura: teoria e prática. Viçosa: Editora UFV, p. 17-30.

Pettigrew, W. T. (2008). Potassium influences on yield and quality production for maize, wheat, soybean and cotton. Physiologia plantarum, v. 133, n. 4, p. 670-681.

Preciado-Rangel, P., Salas-Pérez, L., Gallegos-Robles, M. Á., Ruiz-Espinoza, F. H., Ayala-Garay, A. V., Fortis-Hernández, M., Murillo-Amador, B. (2018). Increasing doses of potassium increases yield and quality of muskmelon fruits under greenhouse. Horticultura Brasileira, v. 36, n. 2, p. 184-188.

Rausch, T; Wachter, A. (2005). Sulfur metabolism: a versatile platform for launching defence operations. Trends in plant science, v. 10, n. 10, p. 503-509.

Ribeiro, A.C. (1999). Recomendações para o uso de corretivos e fertilizantes em Minas Gerais: 5. Aproximação. Comissão de fertilidade do solo do estado de Minas Gerais.

Rodríguez-Navarro, A.; Rubio, F. (2006). High-affinity potassium and sodium transport systems in plants. Journal of Experimental Botany, v. 57, n. 5, p. $1149-1160$

Römheld, V., Kirkby, E. A. (2010). Research on potassium in agriculture: needs and prospects. Plant and soil, 335(1), 155-180.

Santos, A. F., Ribeiro, C.A., Polese, L., Ernandes, J. R., Kesserlingh, S. M., Nonato, R. V. (2006). Determinação de parâmetros de validação de métodos cromatográficos para análise de 5-hidroximetilfurfural e açúcares em amostras de processo de produção de polímero biodegradável. Eclética Química, v. 31, n. 1, p. 13-19.

Silva Curvêlo, C. R., Diniz, L. H. B., de Azevedo Pereira, A. I., Ferreira, L. L. (2018). Influence of fertilizer type on beet production and post-harvest quality characteristic. Agricultural Sciences, 9(05), 557.

Silva, M. A., Vargas, P. H.B., Silva Martins, A. L., Nascimento, K. D. O. (2020). Avaliação do controle de qualidade das frutas e hortaliças comercializadas na feira livre de Valença/RJ. Research, Society and Development, 9(11), e1109119346-e1109119346.

Souza S. P., Mesquita, N.L., Almeida, J. R., Coutrim, R. L., Cairo, P. A.; Silva, L.D. (2020). Crescimento, qualidade de raízes e atividade da redutase do nitrato em plantas de rabanete submetidas a doses de potássio e fontes de nitrogênio. Scientia Plena, v. 16, n. 6.

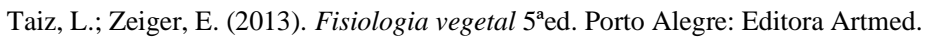

Wang, X. G., Zhao, X. H., Jiang, C. J., Li, C. H., Shan, C. O. N. G., Di, W. U., Wang, C. Y. (2015). Effects of potassium deficiency on photosynthesis and photoprotection mechanisms in soybean (Glycine max (L.) Merr.). Journal of Integrative Agriculture, 14(5), 856-863.

Zhang, B., Dai, D., Huang, J., Zhou, J., Gui, Q., Dai, F. (2018). Influence of physical and biological variability and solution methods in fruit and vegetable quality nondestructive inspection by using imaging and near-infrared spectroscopy techniques: A review. Critical reviews in food science and nutrition, v. 58, n. 12, p. 2099-2118

Zhang, W., Liu, X., Wang, Q., Zhang, H., Li, M., Song, B., Zhao, Z. (2018). Effects of potassium fertilization on potato starch physicochemical properties. International journal of biological macromolecules, v. 117, p. 467-472.

Zhang, X., Wu, H., Chen, L., Liu, L., Wan, X. (2018). Maintenance of mesophyll potassium and regulation of plasma membrane H+-ATPase are associated with physiological responses of tea plants to drought and subsequent rehydration. The Crop Journal, v. 6, n. 6, p. 611-620.

Zheng, H., Zhang, Q., Quan, J., Zheng, Q., Xi, W. (2016). Determination of sugars, organic acids, aroma components, and carotenoids in grapefruit pulps. Food chemistry, v. 205, p. 112-121. 